Special issue of the 2nd International Conference on Computational and Experimental Science and Engineering (ICCESEN 2015)

\title{
Nanomechanical Behaviour and Surface Roughness of New Generation Dental Fissure Sealants
}

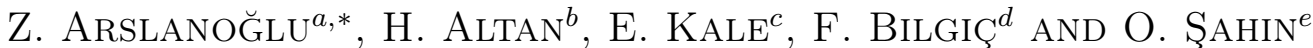 \\ ${ }^{a}$ Mustafa Kemal University Faculty of Dentistry, Department of Paediatric Dentistry, Hatay, Turkey \\ ${ }^{b}$ Gaziosmanpaşa University, Faculty of Dentistry, Department of Paediatric Dentistry, Tokat, Turkey \\ ${ }^{c}$ Mustafa Kemal University Faculty of Dentistry, Department of Prosthodontics, Hatay, Turkey \\ ${ }^{d}$ Mustafa Kemal University Faculty of Dentistry, Department of Orthodontics, Hatay, Turkey \\ ${ }^{e}$ Mustafa Kemal University Faculty of Art and Science, Micro/Nano Mechanic Characterization Laboratory, \\ Hatay, Turkey
}

\begin{abstract}
The aim of this study is the comparative evaluation of surface roughness, elastic modulus and hardness values of some new generation fissure sealants using nanoindentation method and triboindenter. In this study, we have tested five different materials of dental fissure sealant in five groups with six specimens in each. Tested specimens were prepared from the following materials; Fuji Triage as a glass ionomer, Glass Seal as a glass carbomer, Ultra Seal XT Hydro, Teethmate F-1 and Defence Chroma as three resin composites. In the study, Hysitron Triboindenter TI 950 machine was used for nanohardness measurements. This machine has load resolution of less than $1 \mathrm{nN}$ and displacement resolution of $0.04 \mathrm{~nm}$. Data were statistically analysed using one-way analysis of variance (ANOVA) and Kolmogorov-Smirnov Z tests. Hardness values of Fuji Triage, Glass Seal, Ultra Seal XT Hydro were fairly close. Same situation was seen between Teethmate F-1 and Defence Chroma. However, hardness values of the Teethmate F-1 and Defence Chroma was lower than in other examined materials. We can also say that the Defence Chroma has the lowest elastic modulus and Fuji Triage has the highest one among the examined materials. Surface of Teethmate F-1 was the roughest. On the other hand, Ultra Seal XT Hydro has the smoothest surface.
\end{abstract}

DOI: $10.12693 /$ APhysPolA.130.388

PACS/topics: 87.85.J-, 62.20.- $\mathrm{x}$

\section{Introduction}

Pit and fissure areas in the posterior tooth are very sensitive to caries. This is because they play a very good job of giving refuge for the development and proliferation of microorganisms. This situation reduces the efficiency of dental hygiene procedures, makes it difficult to control plaque [1]. It has been reported that occlusal surface of permanent dentition in school children contains 50 percent of dental caries although it constitutes 12.5 percent of the total tooth surface [2]. Thus, for children and adolescent with high caries risk, fissure sealants have been developed to overcome this problem, and it has been applied successfully [3]. The first fissure sealants known in the records were performed by Wilson in 1895 [4]. Fissure sealant has been adopted as an application method for anti-caries in 1971 by American Dental Association [5], and the first commercial product called Nuva Seal (L.D. Caulk Co., Milford, Del., USA) was released on the dental market in the same year [6]. Since then, the application techniques of fissure sealants and major modifications in the used material structure have been experienced $[7,8]$. Nowadays, it is widely used especially in the field of pediatric dentistry at both the deciduous dentition and permanent dentition.

\footnotetext{
* corresponding author; e-mail: zekiarslanoglu@gmail.com
}

Materials used as fissure sealants are divided into three main types: glass ionomer cements, resins and modifications of these materials. Glass ionomer cement (GIC) was developed at the end of 60s in the Laboratory of the Government Chemist in London, UK $[9,10]$ and was introduced to the dental market as the first commercial product called ASPA (aluminosilicate polyacrylic acid) in 1972 [11]. Since then, GIC has been improved to be used in many areas from filling forms to luting agent in dentistry. Firstly, GIC based fissure sealants were introduced by Mclean and Wilson in 1974 [12]. GIC can release fluoride to oral cavity and prevent dental plaque and caries formation in construction at restoration margin up to $3 \mathrm{~mm}[13,14]$.

Recently, glass carbomer cement, which is a GICbased dental restorative material, was developed and introduced by Willem Van Den Bosch and Raimond Nicolaas Van Duinen in 2004. The contents of selfhardening glass carbomer was defined in European patent no. 20040748628 [15] as dialkylsiloxane having terminal hydroxyl groups, wherein the alkyl groups contain 1 to 4 carbon atoms and aqueous acid solution.

Manufacturer and patent owners were claiming that glass carbomer cement, which has just few investigations in literature, has improved physical characteristics and a smoother surface $[15,16]$. Today, the glass carbomerbased fissure sealants are only produced by GCP Dental (Ridderkerk, The Netherlands) commercially. 
Resin based fissure sealants provide good sealing and caries-protective actions because they are well adapted to the fissure wall, and they are resistant to masticatory forces [17]. Due to these features, resin based fissure sealants were most preferred sealants for many years. However, studies in recent years have developed material content and application techniques have provided improvement in physicomechanical properties and ease of application in both types of materials. Today, glass ionomer-based fissure sealants have similar mechanical properties to resin based sealants [17].

Fissure sealants have to remain for many years in the fissure surface to be used as preventive agents effectively. In this regard, the mechanical properties of fissure sealant have been very important in terms of their longevity [18]. If a restorative material is solid and hard as possible, it prevents occurrence of more deformation, under overload. Structural changes occur when the forces are sustained. Initially, this deformation is completely reversible. This behavioral feature is called the elastic strain. An irreversible stretching occurs as a result of continuously increasing force. This feature is also called the plastic stress, and then permanent deformation occurs. The point at which plastic deformation begins is called the elastic limit. If the plastic strain persists, breaks might occur with fracture [19-21]. It is desired in the material selection that elastic limit of material will not exceed the compression level that occurs during function [19, 21].

Beginning of plastic deformation of different materials is usually compared when elastic limit is measured, and drawing and immersion tests which are also known as hardening tests are used for this purpose [20, 21]. Vickers, Knoop, Brinell and Rockwell are tests that have been widely used for measuring the hardness of dental materials. Nanoindentation tests capable of measuring much smaller values and obtaining reliable results have been developed, apart from these conventional methods. All these methods have in common the penetration of a small and geometric end into the surface of the material, hardness of which is being measured [22]. Nanoindentation tests have been reported as very powerful methods for measurement of the mechanical properties of materials, which include particles with very small sizes, such as nanocomposites, tooth enamel and bone cement [23, 24].

In some studies, plaque accumulation has been reported to increase further above certain threshold value of surface roughness in dental restorations [25]. At the same time, smooth and highly polished surface provides patient comfort in the dental restorations, more denture longevity, oral hygiene and good aesthetics in addition to low plaque retention [26]. Thus, smoothness after polishing is very important in the dental restorations.

The purpose of this study is the comparative evaluation of surface roughness, elastic modulus and hardness values of some of new generation fissure sealants using nanoindantation method and triboindenter. The null hypothesis of the study is that there is no difference between the materials to be tested.

\section{Materials and methods}

\subsection{Preparation of samples}

In this study, we have tested five different materials of dental fissure sealants in five groups with six specimens of each. Tested specimens were prepared from glass ionomer - Fuji Triage (FT), glass carbomer - Glass Seal (CARB), resin - Ultra Seal XT Hydro (UXT), resin - Teethmate F-1 (TETM) and resin - Defence Chroma (DEFC) (see Table I).

TABLE I

Brand names, specifications and manufacturers of materials used in the study.

\begin{tabular}{c|c|c}
\hline \hline Material brand name & Specification & Manufacturer \\
\hline Fuji Triage & Glass ionomer & GC Corp., Japan \\
GCP Glass Seal & Glass carbomer & GCP Dental, NL \\
Ultra Seal XT Hydro & Resin compos. & Ultradent, USA \\
Teethmate F-1 & Resin compos. & Kuraray, Japan \\
Defence Chroma & Resin compos. & Angelus, Brazil
\end{tabular}

Thirty pieces of polymethylmethacrylate (PMMA) cylinders with parallel edges were fabricated $10 \mathrm{~mm}$ thick and $50 \mathrm{~mm}$ in diameter. Cavities with $2 \mathrm{~mm}$ depth and $10 \mathrm{~mm}$ in diameter were prepared in the centre of one of flat surfaces of each cylinder block. Ultrathin layer of cyanoacrylate (CA) adhesive treatment was applied to the inner surfaces of prepared cavity.

The prepared PMMA blocks were randomly divided into 5 groups, each containing 6 cylinders, and each cavity was filled with the appropriate test materials according to their group.

For Group 1, the prepared cavities were filled with FT. Material was mixed for 10 seconds with a capsule mixer Linea Tac $400 \mathrm{M}$ in accordance with the manufacturer's instructions, and Fuji Applicator was used to place material into the cavity.

Cavities prepared in Group 2 were filled with CARB. Material was mixed for 10 seconds with a capsule mixer GCP CarboMIX in accordance with the manufacturer's instructions, and GCP carboCAP Applicator was used to place material into the cavity. The samples of the group were covered with GCP Gloss, and then $1400 \mathrm{~mW}$ light-heating procedure with GCP Carboled Lamp was applied for $60 \mathrm{~s}$ of light-curing.

Cavities prepared in Group 3 were filled with UXT and $1400 \mathrm{~mW}$ light procedure with GCP Carboled Lamp was applied for $20 \mathrm{~s}$ of light-curing.

Cavities prepared in Group 4 were filled with TETM and $1400 \mathrm{~mW}$ light procedure with GCP Carboled Lamp was applied for $20 \mathrm{~s}$ of light-curing.

Cavities prepared in Group 5 were filled with DEFC and $1400 \mathrm{~mW}$ light procedure with GCP Carboled Lamp was applied for $20 \mathrm{~s}$ of light-curing.

Samples were incubated in distilled water in the lightproof plastic tube at $37^{\circ} \mathrm{C}$ for $23 \mathrm{~h}$, separated from each other. After $23 \mathrm{~h}$ each sample was prepared. Procedures were performed respectively to eliminate irregularities formed in the surface, to bring to the same level 
the material surface and the cylinder surface and to ensure parallelism required for the measurement of material surface. In this regard, sample surfaces were flattened mechanically by grinding with 1200 and 2400 grit (SiC) sandpaper according to the procedures of manual applications. Later, it was polished with 6, 3 and 1 nanodiamond lap wheels.

\subsection{Methods}

In this study, nanohardness measurements were performed using Hysitron Triboindenter TI 950 machine. Load resolution of this machine is less than $1 \mathrm{nN}$ and displacement resolution is $0.04 \mathrm{~nm}$. Berkovich diamond indenter tip was used in measurement of nanohardness and reduced elastic modulus of specimens. The tip was calibrated using a fused quartz reference sample. In order to record the morphological images of the indents, the nanoindenter was also operated in scanning probe mode. Surface roughness of the samples was measured using scanning probe microscopy (SPM). In this study, maximum load was determined to be $6000 \mu \mathrm{N}$ under a loading/unloading rate of $1200 \mu \mathrm{N} \mathrm{s}^{-1}$, and the load was held at each maximum value for $2 \mathrm{~s}$. For a particular load at least five indentation tests were conducted on the sample surface to increase the reliability of the experimental results. Oliver-Pharr [27] method was used to analyse the nanoindentation load-displacement curves. In this model contact area and nanohardness were defined as,

$$
H_{\mathrm{nano}}=\frac{P_{\max }}{A},
$$

$$
A_{c}=24.5 h_{c}^{2}
$$

where $P_{\max }$ is the maximum test load and $A$ is the projected contact area at $P_{\max }$. For a perfect Berkovich indenter the projected contact area is given by Eq. (2). The reduced elastic modulus $E_{\mathrm{r}}$ is calculated as

$$
E_{\mathrm{r}}=\frac{\sqrt{\pi}}{2} \frac{S}{\sqrt{24.5} h_{c}} .
$$

Here $S$ is the contact stiffness that is computed from the initial slope of the unloading curve at $P_{\max }$. Detailed procedures were given in the literature [28, 29].

In this work, we have used the aforementioned computational procedure to calculate the nanohardness and elastic modulus of the five different dental fissure sealants. Surface roughness values were measured by SPM at the attached nanoindenter.

The data was statistically analysed using one-way analysis of variance (ANOVA) at the level of significance $p<0.05$. Furthermore, Kolmogorov-Smirnov Z test was used for sample distributions. Analysis was performed using the SPSS statistical software (Statistical Package for the Social Sciences, SPSS Inc, Chicago, IL, USA).

\section{Results}

Load-displacement curves obtained during nanoindentation tests for dental fissure sealants are shown in Fig. 1.
The figure exhibits five different load-unload indentation cycles of test materials. The curve demonstrates a smooth shape, and no pop-in could be detected. The nanohardness and elastic modulus values were calculated according to the Oliver-Pharr model using the applied indentation test load-displacement curves. As one can see from the SPM micrograph of CARB1 sample (Fig. 1), the sample surfaces are homogeneous and without cracks. Furthermore, we believe that there is no significant surface finishing effect since the shape of the Berkovich indenter is exactly the same as the indentation observed on the sample surface. Therefore, it is judged to be unnecessary to discuss the effect of microcracking on the nanohardness measurements in this study.

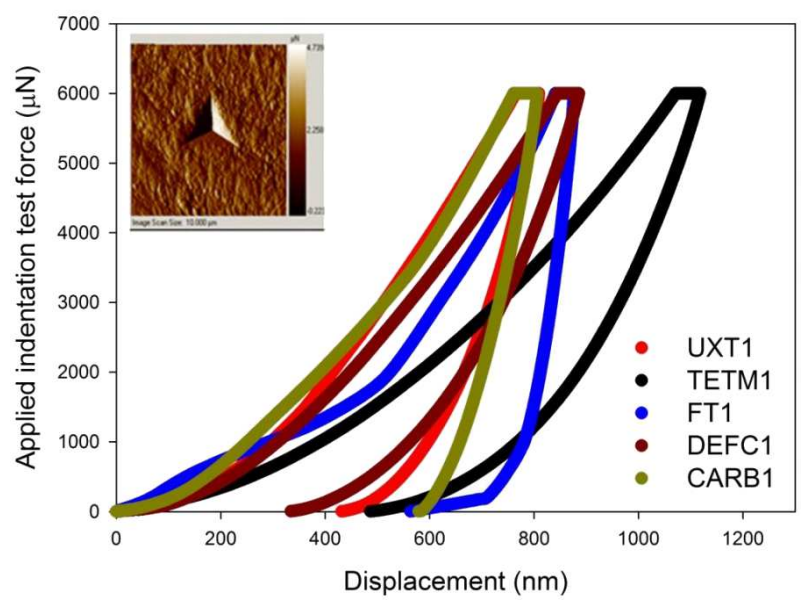

Fig. 1. Applied indentation test force versus displacement of tested materials.

Nanohardness and elastic modulus values of these samples were calculated using Eq. (1) and Eq. (3), respectively. These values are given in Table II and Fig. 2. Hardness values of FT, CARB, UXT were fairly close $(p>0.05)$. Same situation was seen between TETM and DEFC $(p>0.05)$. However, hardness values of the TETM and DEFC are lower than in the other examined materials $(p<0.05)$.

TABLE II

Average values of hardness $H$ and elastic modulus $E r$ of the specimens.

\begin{tabular}{c|c|c}
\hline \hline Sample name & $E r[\mathrm{GPa}]$ & $H[\mathrm{GPa}]$ \\
\hline FT & $12.29 \pm 1.060$ & $0.510 \pm 0.010$ \\
CARB & $10.633 \pm 0.780$ & $0.490 \pm 0.015$ \\
UXT & $10.113 \pm 1.150$ & $0.490 \pm 0.010$ \\
TETM & $4.091 \pm 0.230$ & $0.262 \pm 0.013$ \\
DEFC & $3.294 \pm 0.048$ & $0.284 \pm 0.011$
\end{tabular}

On the other hand, elastic modulus can be described as a material's tendency to be deformed elastically when a force is applied to it. In other words, it was fundamentally related to the bond strength between the atoms or molecules in the material; that is, the stronger the bond, 
the higher the elastic modulus. According to our experimental results, thus, we can also say that the DEFC has the most weak bond strength. On the other hand, FT has the most strong bond strength among the examined materials.
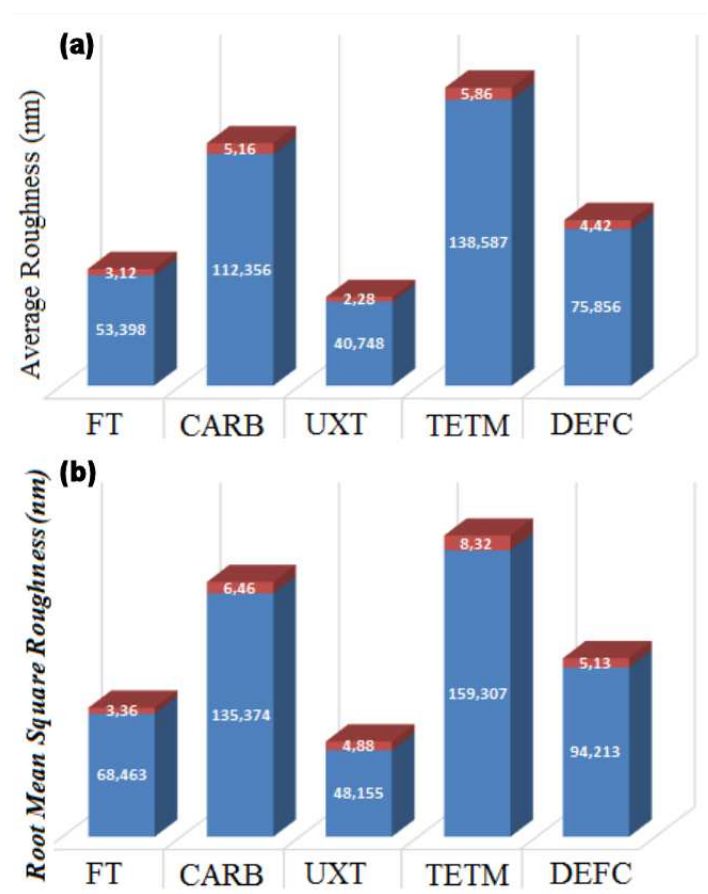

Fig. 2. Hardness (a) and elastic modulus (b) of the tested samples.

The results of the roughness measurements are presented in Table III and Fig. 3.

TABLE III

Average roughness $R a$ and root mean square roughness $R q$ values of the specimens.

\begin{tabular}{c|c|c}
\hline \hline Samples code & $\begin{array}{c}\text { Average roughness } \\
R a[\mathrm{~nm}]\end{array}$ & $\begin{array}{c}\text { Root mean square } \\
\text { roughness } R q[\mathrm{~nm}]\end{array}$ \\
\hline FT & $53.398 \pm 3.12$ & $68.463 \pm 3.36$ \\
CARB & $112.356 \pm 5.16$ & $135.374 \pm 6.46$ \\
UXT & $40.748 \pm 2.28$ & $48.155 \pm 4.88$ \\
TETM & $138.587 \pm 5.86$ & $159.307 \pm 8.32$ \\
DEFC & $75.856 \pm 4.42$ & $94.213 \pm 5.13$
\end{tabular}

\section{Discussion}

Many studies have been performed about structural features of dental pit and fissure sealants, showing their superiority over each other $[2,7,14]$. At present, many clinicians have access to pit and fissure sealants, used for the same kind of job. Some of these may vary in the content of filler particles while the others may vary in many ways such as capability of fluoride release, flow capability, characteristics of radio opacity or colour. In this
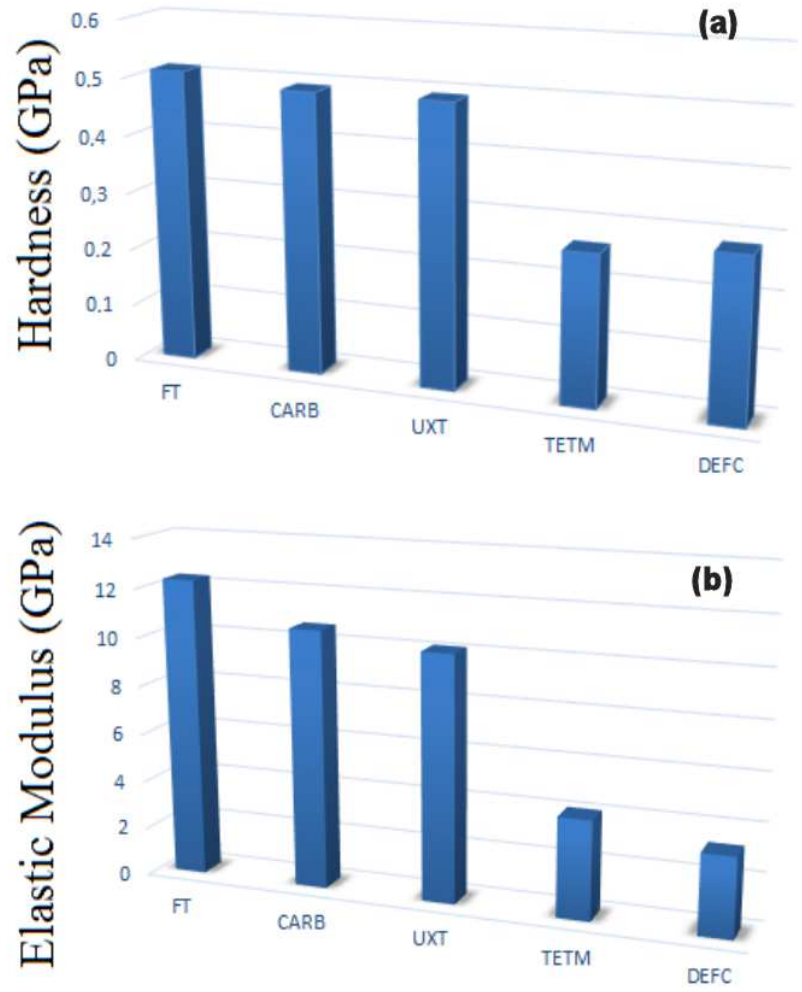

Fig. 3. Average (a) and root mean square (b) roughness of the tested materials.

wide range of materials, mechanical properties have vital importance for resistance to masticatory forces and effective use of restorations [18]. Restorations that do not have sufficient mechanical properties are broken and get lost. Thus, fissure surfaces become able to decay again. This study was planned for taking into account the importance of the mechanical properties of pit and fissure sealants.

Indentation hardness, widely used as the principal parameter for the mechanical characterization, is a measuring technique for mechanical properties of material. In practice, there are two different methods including conventional and dynamic. The main disadvantage of the conventional method is the facet contact area measured after the load is removed. Scientists have been suggesting that area may be susceptible to elastic recovery [30]. The other disadvantage is measuring by tracing very small size of formed penetration depths using the solid optic microscope. It is difficult to make the optical measurements with a high degree of accuracy for notches formed in this case. Therefore, conventional indentation hardness obtained from notch by optical observations does not provide reliable information about the material mechanical properties. The method used for determining the mechanical properties of solids is the nanoindentation method, known as dynamic hardness. This method offers great advantages over conventional methods. Firstly, it allows obtaining well defined mechanical parameters such as the elastic modulus of the 
interfacial zone besides the hardness. Secondly, it provides monitoring of the load and depth of an indentation continuously [30, 31]. Because of this, nanoindentation method, which has many advantages compared to conventional methods, was used in this study.

Considering the history of literature, mechanical properties of dental materials are examined mostly by conventional methods, because of easier access to such measurement. Use of nanoindentation method has been possible with the development of nanotechnology in recent years and the development of dental materials containing nanoparticles [15]. Size of filler particles of new generation of dental pit and fissure sealant materials used in our current study is too small, which makes it appropriate to use the nanoindentation method.

Another important objective is the smoothest surface, which is desired to be obtained at the end of dental restoration. The surface properties of the restoration are measured by roughness value, and this value is calculated by taking the arithmetic mean of deviation from the main line of roughness profile [27]. In our research, polishing machine was used to prepare the surface of sample and to standardize the force applied to the test surface. Bollen roughness of tooth surfaces was considered while surfaces were prepared. Bollen has claimed that the accumulation of plaques increases at the surfaces where the roughness value is above $0.20 \mathrm{~nm}$ and this brings with it many undesirable situations from oral hygiene to the caries. This theory has been accepted by scientists, and surface roughness in terms of value is recognized as the threshold value [19, 20, 32]. Roughness value of prepared samples in our study is below $0.20 \mathrm{~nm}$.

\section{Conclusions}

Within the limitation of this study the following conclusions can be drawn:

- Fuji Triage, Glass Seal and Ultra Seal XT Hydro have shown the best physical strength $(p<0.05)$. Hardness values of these groups were very close to each other, so statistically there was no dissimilarity $(p>0.05)$.

- Teethmate F-1 and Defence Chroma exhibited the lowest hardness values $(p<0.05)$. Hardness values of these groups were very close to each other, so statistically there was no dissimilarity $(p>0.05)$.

- Elastic modulus values of Defence Chroma was the lowest $(p<0.05)$. Elastic modulus values of Fuji Triage was the highest one $(p<0.05)$.

- Surface of Teethmate F-1 was the roughest one, on the other hand, Ultra Seal XT Hydro was the smoothest $(p<0.05)$.

- Thus, after the developments in dental materials, the glass ionomer based fissure sealants have as superior mechanical properties as the resin based.

\section{Acknowledgments}

This work is supported by Turkish State Planning Organization (DPT) with project No: 2010K121220 and it is also supported by the scientific research Commission of Mustafa Kemal University (BAP) (Project No: 12880).

\section{References}

[1] J.B. Dennison, R.G. Craig, in: Restorative dental materials, Eds. R.G. Craig, J.M. Powers, Mosby, St. Louis 2002, p. 199.

[2] S. Beun, C. Bailly, J. Devaux, G. Leloup, Dent. Mater. 28, 349 (2012).

[3] A.A. Oba, T. Dülgergil, I.S. Sönmez, S. Doğan, J. Formos. Med. Assoc. 108, 844 (2009).

[4] I.P. Wilson, Dent. Digest. 1, 70 (1895).

[5] Council on dental materials and devices, Council on dental therapeutics, J. Am. Dent. Association 82, 1101 (1971).

[6] R.J. Simonsen, Pediatr. Dent. 24, 393 (2002).

[7] K.R. Powell, R.G. Craig, J. Dent. Res. 57, 691 (1978).

[8] N.A. Lygidakis, K.I. Oulis, A. Christodoulidis, J. Clin. Pediatr. Dent. 19, 23 (1994).

[9] M.R. Towler, A.J. Bushby, R.W. Billington, R.G. Hill, Biomaterials 22, 1401 (2001).

[10] B.E. Kent, A.D. Wilson, Br. Dent. J. 135, 322 (1973).

[11] A.D Wilson, J.W. McLean, Glass-Ionomer Cement, Quintessence Pub., Berlin 1988.

[12] I. Mejàre, I.A. Mjör, Scand. J. Dent. Res. 98, 345 (1990).

[13] S.R. Anand, H. Mythri, J. Clin. Exp. Dent. 6, e497 (2014).

[14] M. Aranda, F. Garcia-Godoy, J. Clin. Pediatr. Dent. 19, 273 (1994).

[15] Z. Arslanoğlu, H. Altan, O. Şahin, M.G. Tekin, M. Adıgüzel, Acta. Phys. Pol. A. 128, B-310 (2015).

[16] W.F. Van Den Bosch, N.B. Van Duinen Raimond, Self-hardening glass carbomer composition, European Patent Number: 20040748628, 1 Mar 2006.

[17] S. Şimşek Derelioğlu, Y. Yılmaz, P. Çelık, B. Çarıkcıŏlu, S. Keleş, Dent. Mater. J. 33, 530 (2014).

[18] S. Tavassoli-Hojjati, M. Atai, R. Haghgoo, S. Rahimian-Imam, S. Kameli, F. Ahmaian-Babaki, F. Hamzeh, M. Ahmadyar, J. Dent. (Tehran). 11, 379 (2014).

[19] M. Ersoy, E. Özel, K. Gökçe, J. Dent. Fac. Atatürk. Uni. 17, 28 (2007).

[20] V. Türel, J. Dent. Fac. Atatürk. Uni. 11, 77 (2015).

[21] T.M. Robenson, H.O. Heymann, E.J. Swift, Sturdevant's Art and Science of Operative Dentistry, Mosby, St. Louis 2006.

[22] W.J. O'Brien. Dental Materials and Their Selection, Quintessence Pub., Canada 2002.

[23] M. Shokrieh, M. Hosseinkhani, M. Naimi-Jamal, H. Tourani, Polym. Test. 32, 45 (2013). 
[24] M.R. Ayatollahi, M.Y. Yahya, A. Karimzadeh, M. Nikkhooyifar, A. Ayob, Mater. Sci. Eng. C. Mater. Biol. Appl. 54, 69 (2015).

[25] M.A. Abuzar, S. Bellur, N. Duong, B.B. Kim, P. Lu, N. Palfreyman, D. Surendran, V.T. Tran, J. Oral. Sci. 52, 577 (2010).

[26] T. Pereira-Cenci, A.A. Del Bel Cury, W. Crielaard, J.M. Ten Cate, J. Appl. Oral. Sci. 16, 86 (2008).

[27] W.C. Oliver, G.M. Pharr, J. Mater. Res. 7, 1564 (1992).

[28] O. Şahin, O. Uzun, U. Kölemen, N. Uçar, Material Characterization 59, 729 (2008).
[29] O. Sahin, O. Uzun, M. Sopicka-Lizer, H. Göçmez, U. Kölemen, J. Phys. D: Appl. Phys. 41, 8 (2008).

[30] K. Schultz, M. Durst, Filtr. Separat. 31, 25 (1994).

[31] O. Şahin, O. Uzun, M. Sopicka-Lizer, H. Göçmez, U. Kölemen, J. Eur. Ceram. Soc. 28, 1235 (2008).

[32] M. Quirynen, H.C. Van Der Mei, C.M. Bollen, A. Schotte, M. Marechal, G.I. Doornbusch, H.J. Busscher, D. Van Steenberghe, J. Dent. Res. 72, 1304 (1993). 